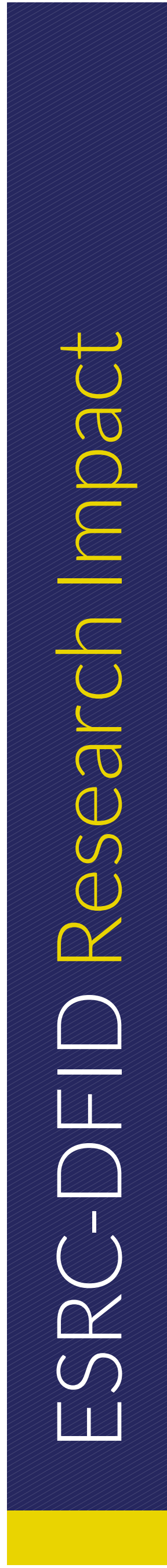

\title{
HELPING TO MAKE SAFE ABORTION A REALITY IN ZAMBIA
}

Zambia has one of the most liberal abortion laws in sub-Saharan Africa. However, in spite of this, unsafe abortion continues to contribute to high rates of maternal mortality. Stigma, poverty, conscientious objectors, and lack of knowledge all contribute to why many adolescent girls and women do not and cannot access safe abortions in Zambia. Through ground-breaking research led by the London School of Economics and Political Science (LSE), political, media, and charitable organisations are now making changes to raise awareness and shape their frameworks to ensure women can take up their right to access safe abortion services.

\section{THE CHALLENGE}

Under the Termination of Pregnancy Act of 1972,

Zambian law asserts that women have the right to safe and legal abortion services. But very few people know about the law, or the services available, and there is still an enormous amount of stigma associated with abortion.

Worldwide, approximately 25 million unsafe abortions are carried out each year and death from unsafe abortion disproportionately affects women in Africa (WHO 2018). In Zambia, the government estimates that 30 per cent of maternal deaths are attributable to unsafe abortion.

\section{THE RESEARCH}

The researchers wanted to understand the roles that the health system, poverty, and stigma can play in seeking abortion-related care in Zambia; estimate and compare the implications of safe abortion and post-abortion care for women and their households; and ultimately better understand how and why safe abortion services are not used more fully.

Based at a Zambian Government Health Facility in Lusaka, the researchers interviewed over 100 girls and women coming either for an abortion or for postabortion care after an unsafe abortion. The research team worked closely with midwives to gain informed

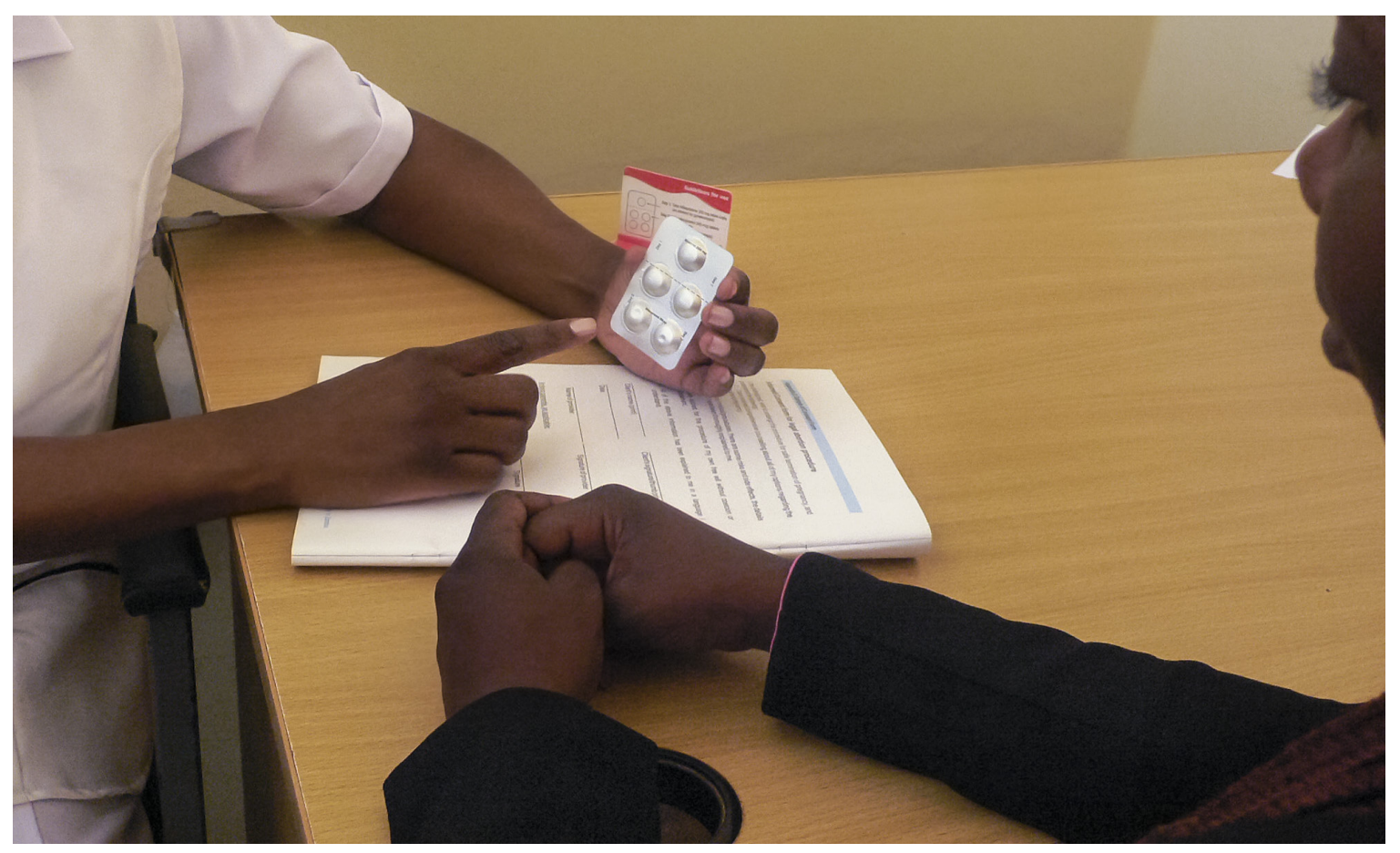

Cover photo: Medical abortion consultation in Zambia. Credit: Dr Ernestina Coast 
and considered consent from all the participants.

In addition to the dangerous and often life-threatening impact of unsafe abortion, the research identified a significant public health cost. The first national estimates showed that treating the consequences of unsafe abortion costs the Zambian health system up to US\$0.4 million more than if the pregnancies had been terminated safely and legally.

The study found that younger and poorer women are more likely to have an unsafe abortion, even though the costs of unsafe abortion for individual women are 27 per cent higher than the costs associated with a safe abortion. It also revealed that women often have to make 'unofficial payments' to doctors for services that should be free.

'Luck' or 'chance' plays a primary role in determining whether a woman can have a safe and legal abortion. Quite often, where a woman feels she can disclose to someone that she is pregnant or if she knows someone in the health sector she may get the services she needs. Otherwise, women may not know these services exist, and if they need to hide their pregnancy or abortion they take great risks in order to terminate an unsustainable pregnancy.

Raising awareness of these services - targeting not just the general population, but also health professionals - is vital if the Zambian Government is to reap the rewards of their investment in the provision of safe and legal abortion services.

\section{THE IMPACT}

The research team have been - and continue to be - proactive in engaging key people, organisations, and institutes to support progress to successfully implement and deliver safe and legal abortion services. Through working with government, media, and nongovernmental organisation (NGO) actors, this research has gone beyond Zambia solely as a country study, and is shining a spotlight on the complex and challenging process of how to provide abortio $n$ care.

Media engagement has included the researchers being involved in training Zambian radio producers who work on programmes for young adults. In-country partners also gave interviews on BBC World News, and programmes on the Zambian National Broadcasting Corporation (ZNBC), commercial radio, and a radio station for young adults.

The Zambian lead for the project presented the findings to the Resident Doctors Association of Zambia (RDAZ) in 2015, during which he found that newly graduated doctors were unaware of the laws around abortion in Zambia. The guest of honour was the Deputy Minister of Health, who subsequently invited the partner to present at the Senior Management meeting of the Ministry of Health. The research has also been incorporated in the latest Standards and Guidelines for Comprehensive Abortion Care in Zambia.

\section{FURTHER READING}

LSE (London School of Economics) (2015) 'Zambia Urged to Tackle the Stigma of Abortion and Unwanted Pregnancies', Firoz Lalji Centre for Africa blog, 11 June, http://blogs.Ise.ac.uk/africaatlse/2015/06/11/zambiaurged-to-tackle-the-stigma-of-abortion-and-unwantedpregnancies/ (accessed 28 June 2018)

Parmar, D.; Leone, T.; Coast, E.; Fairley Murray, S.; Hukin, E. and Vwalika, B. (2017) 'Cost of Abortions in Zambia: A Comparison of Safe Abortion and Post Abortion Care', LSE Research Online, http://eprints. Ise.ac.uk/63643/1/ Ise.ac.uk storage LIBRARY Secondary libfile shared repository Content Coast,\%20E_Cost\%20of\%20abortions_Coast_ Cost\%20of\%20abortions_2016.pdf (accessed 28 June 2018)

WHO (2018) WHO Preventing Unsafe Abortion, World Health Organization Fact Sheet, www.who.int/newsroom/fact-sheets/detail/preventing-unsafe-abortion (accessed 28 June 2018)

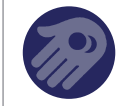

Pregnancy Termination Trajectories in Zambia: The Socio-Economic Costs

The research was funded by the Economic and Social Research Council (ESRC) and the UK's Department for International Development (DFID) Joint Fund for Poverty Alleviation Research. The study 'Pregnancy Termination Trajectories in Zambia' was carried out by Dr Ernestina Coast, Dr Tiziana Leone, Dr Emily Freeman, and Dr Eleanor Hukin (London School of Economics); Dr Bellington Vwalika (University Teaching Hospital, Zambia); Dr Bornwell Sikateyo (University of Zambia); Dr Susan Murray (Kings College London); and Dr Divya Parmar (City, University of London).

\section{THE IMPACT INITIATIVE}

\section{For International Development Research}

The Impact Initiative seeks to connect policymakers and practitioners with the world-class social science research supported by the ESRC-DFID Strategic Partnership, maximising the uptake and impact of research from: (i) the Joint Fund for Poverty Alleviation Research, and (ii) the Raising Learning Outcomes in Education Systems Programme. We seek to identify synergies between these programmes and their grant holders, support them to exploit influencing and engagement opportunities, and facilitate mutual learning. The Impact Initiative is a collaboration between the Institute of Development Studies (IDS) and the University of Cambridge's Research for Equitable Access and Learning (REAL) Centre.

All content is available under the Open Government License v3.0, except where otherwise stated.

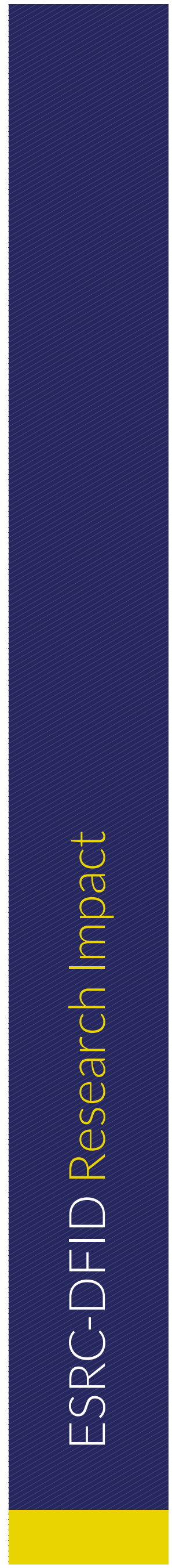

